\title{
Desempenho e Características de Carcaça de Machos Revertidos de Tilápias do Nilo (Oreochromis niloticus), Linhagens Tailandesa e Comum, nas Fases Inicial e de Crescimento
}

\author{
Wilson Rogério Boscolo ${ }^{1}$, Carmino Hayashi ${ }^{2}$, Claudemir Martins Soares ${ }^{3}$, Wilson Massamitu \\ Furuya $^{4}$, Fábio Meurer ${ }^{1}$
}

\begin{abstract}
RESUMO - O experimento foi conduzido objetivando comparar o desempenho de duas linhagens de tilápia do Nilo (tailandesa e comum) durante as fases inicial e de crescimento. Os animais (50 na fase inicial e 40 na fase de crescimento) foram distribuídos em um delineamento inteiramente casualizado com dois tratamentos e cinco repetições. Foram observados melhores resultados para a porcentagem de ganho de peso, ganho de peso diário, conversão alimentar, viabilidade econômica em ambas as fases experimentais, sobrevivência na fase inicial e comprimento final na fase de crescimento para os animais da linhagem tailandesa. Na fase de crescimento, os valores de rendimento de carcaça (animais sem o trato digestório e arcos branquiais) e de filé não apresentaram diferenças estatísticas entre os tratamentos, entretanto, o rendimento de tronco (carcaça sem cabeça, pele e nadadeiras dorsal, ventral e peitoral) foi superior para os animais da linhagem comum. De acordo com as características morfométricas, foi observada maior relação entre o comprimento da cabeça/altura da cabeça e comprimento padrão/comprimento total para os animais da linhagem tailandesa e maior relação entre a largura do corpo e o comprimento do tronco para os animais da linhagem comum. Não foi observada diferença na relação entre a altura do corpo/comprimento do tronco entre as linhagens estudadas. Os animais da linhagem tailandesa apresentaram melhores resultados de desempenho nas fases inicial e de crescimento, porém apresentaram cabeça maior e cauda menor.
\end{abstract}

Palavras-chave: carcaça, desempenho, linhagens, Oreochromis niloticus, tilápia do Nilo

\section{Performance and Carcass Characteristics of Nile Tilapia (Oreochromis niloticus) Reversed Males of Thai and Common Strains at the Starting and Growing Phases}

\begin{abstract}
The experiment was carried out to compare the performance of two Nile Tilapia strains (Thai and common) during the initial and growing phases. The fishes (50 in the starting phase and 40 in the growing phase) were assigned to a completely randomized design with two treatments and five replications. Better results were observed for the weight gain percentage, daily weight gain, feed:gain ratio and economic viability in both experimental phases, survival in the starting phase and final size in the growing phase for the Thai strain animals. In the growing phase, carcass (animal without the digest tract and branchial arcs) and filet yield showed no statistical differences among the treatments, however trunk yield (carcass without head, dorsal, ventral and pectoral skin and fins) were higher for the common strain animals. According to the morphometrical characteristics, higher relation between the head length/head height and standard length/total length for the Thai strain animals and a higher body width/trunk length relation for the common strain animals were observed. No difference was observed for the body height/trunk length relation for the studied strains. Thai strain animals showed better performance results in the initial and growing phases, however presented bigger head and smaller tail.
\end{abstract}

Key Words: carcass, Nile tilapia, Oreochromis niloticus, performance, strains

\section{Introdução}

Tilápia é a denominação comum de grande gama de espécies de peixes ciclídeos, que, conforme POPMA e PHELPS (1998), se distribuem originalmente do centro - sul da África até o norte da Síria. Cerca de 22 espécies de tilápia são cultivadas no mundo, porém a tilápia do Nilo (Oreochromis niloticus), a tilápia mossâmbica (O. mossambicus), a tilápia azul (O. aureus), O. maccrochir, O. hornorum, O. galilaeus, Tilapia zillii e a $T$. rendalli são as espécies mais criadas comercialmente (EL-SAYED, 1999).

De acordo com LOVSHIN (1997), a distribuição das tilápias pelo mundo começou com o intuito da criação de peixes para a subsistência em países em desenvolvimento. A primeira espécie introduzida em

\footnotetext{
${ }^{1}$ Programa de Pós-Graduação em Zootecnia/Universidade Estadual de Maringá. Av. Colombo, 5790, Jardim Universitário, Maringá - PR. E.mail:wrboscolo@bol.com.br;f-meurer@bol.com.br

2 Professor Titular do Depto.de Biologia/UEM.E.mail: chayashi@uem.br

3 Biólogo do Laboratório de Aqüicultura, Depto de Biologia/UEM.E.mail: cmsoares@uem.br

4 Professor Adjunto do Depto de Zootecnia/UEM.E.mail:wmfuruya@uem.br
} 
outros países foi a $O$. mossambicus, porém esta mostrou-se de baixo desempenho para a aquicultura (LAZARD e ROGNON, 1997). Entretanto, de acordo com Lazard (1984), citado por LAZARD e ROGNON (1997), no final dos anos 70, a espécie $O$. niloticus demonstrou alto potencial para a aqüicultura, em vários sistemas de criação.

No Brasil, a tilápia do Nilo, proveniente da Costa do Marfim no Oeste africano, foi introduzida no nordeste em 1971 e, então, distribuída pelo país. A tilápia do Nilo e algumas tilápias vermelhas híbridas são as espécies mais cultivadas no Brasil. A tilápia do Nilo é cultivada desde a bacia do rio Amazonas até o Rio Grande de Sul. O interesse pelo cultivo desta espécie, no sul e sudoeste do país, cresceu rapidamente nos últimos oito anos pela introdução da tecnologia da reversão sexual e a pesca esportiva, representado pelos pesque-pagues. A tilápia é criada em diversos sistemas desde a cultura semi-intensiva em tanques que recebem dejetos animais como em cultivo intensivos em "raceways" e tanques-rede. Acredita-se que, no Brasil, metade da produção anual de peixes cultivados seja de tilápias (LOVSHIN e CIRYNO, 1998).

A tilápia do Nilo destaca-se como peixe de potencial para aquicultura, visto a sua rusticidade, crescimento rápido e adaptação ao confinamento (HAYASHI, 1995); possui hábito alimentar onívoro, e aceita rações com grande facilidade, desde o período de pós-larva até a fase de terminação. De acordo com POPMA e PHELPS (1998), a tilápia é, entre as espécies de peixes mais cultivadas, a que melhor resiste a alta temperatura, a baixa concentração de oxigênio dissolvido e a alta concentração de amônia na água. Já LAHAV e RA'NAM (1997) citam que a principal vantagem da tilápia do Nilo é o seu baixo custo relativo, principalmente quanto ao alevino, à alimentação e à qualidade da sua carne. A espécie de tilápia preferida para o cultivo é a O. niloticus, por causa do seu rápido crescimento e sua coloração clara (LOVSHIN, 1997).

No Brasil, um segmento responsável pelo grande incremento da produção é o sistema de "pesquepague", que nos últimos anos ampliou em muito a sua demanda (BORGHETTI e OSTRENSKY, 1998).

Recentemente, foi introduzida no Brasil uma nova variedade de tilápia do Nilo vinda da Tailândia (LOVSHIN, 1998). Em 1996, com o objetivo de melhorar geneticamente o plantel existente no Estado do Paraná, a Associação Paranaense dos Produtores de Alevinos (ALEVINOPAR), com o apoio da Empresa Brasileira de Assistência Técnica e Extensão Rural
(EMATER) e de outros órgãos governamentais, importaram matrizes de tilápias do Nilo da Tailândia.

Avaliando três espécies de tilápia ( $O$. niloticus, O. aureus e $O$. mossambicus) a progênie híbrida (O. niloticus x $O$. aureus) e a tilápia tailandesa vermelha (O. mossambicus x O. niloticus), SIDDIQUI e AL-HARBI (1995) observaram diferenças entre as diferentes espécies e cruzamentos, com melhor desempenho para tilápia híbrida (O. niloticus x $O$. aureus), seguida pela $O$. niloticus e $O$. aureus e pior desempenho da $O$. mossambicus. Já a tilápia vermelha apresentou pior taxa de sobrevivência (7\%), demonstrando, portanto, que pode haver diferenças no desempenho de diferentes espécies criadas em mesmas condições.

Levando-se em consideração as significativas diferenças de desempenho apresentadas entre as diversas linhagens de outras espécies de animais domésticos, como em aves, suínos e bovinos, e a importância econômica da tilápia do Nilo para a aquicultura, fazem-se necessários estudos para avaliar o desempenho das diferentes linhagens de O. niloticus cultivadas no Brasil.

O presente trabalho teve por objetivo comparar o desempenho, características de carcaça e características morfométricas de tilápias do Nilo (O. niloticus) das linhagens tailandesa e comum nas fases inicial e de crescimento.

\section{Material e Métodos}

Foram realizados dois experimentos, com animais das linhagens comum e tailandesa. O primeiro, na fase inicial, foi realizado durante o período de 08/04 a 28/05 de 1998, enquanto o segundo, na fase de crescimento, foi realizado durante o período de 09/02 a 12/04 de 1999, ambos conduzidos no Laboratório de Aqüicultura do Departamento de Biologia da Universidade Estadual de Maringá. Foram considerados como linhagem comum os animais provenientes de planteis de duas pisciculturas da região norte do Paraná e como linhagem tailandesa animais de segunda geração de um lote importado da Tailândia.

No primeiro experimento (fase inicial) foram utilizados 50 alevinos revertidos, sendo 25 de cada linhagem, que foram distribuídos em um delineamento inteiramente casualizado com dois tratamentos e cinco repetições, onde cada unidade experimental foi constituída por um aquário com cinco animais. $\mathrm{O}$ peso vivo inicial médio para os animais das variedades tailandesa e comum foram de 2,94 $\pm 0,22$ e 2,37 $\pm 0,30 \mathrm{~g}$, respectivamente, que foi distribuídos em 10 aquários, 
com capacidade para $50 \mathrm{~L}$, com sistema de aeração contínuo por meio de pedras micro-porosas conectadas a compressores de ar portáteis e temperatura controlada por aquecedores de $150 \mathrm{~W}$ com termostato.

A água dos aquários era renovada a uma taxa de $40 \%$ do volume total/dia, através de sifonagem realizada duas vezes ao dia, uma no período da manhã antes da primeira alimentação e outra no período da tarde, antes da última alimentação, este manejo foi realizado também com o objetivo de retirar as fezes depositadas no fundo dos aquários.

Para a alimentação utilizou-se ração comercial peletizada com $3000 \mathrm{kcal} \mathrm{ED} / \mathrm{kg}$ e $32,00 \%$ de proteína bruta (PB) (Tabela 1) na proporção de $10 ; 8$ e 5\% do peso vivo, nos períodos de 1-7; 8-14 e 15 a 50 dias de experimento, respectivamente. A taxa de arraçoamento foi corrigida semanalmente por intermédio da pesagem de todos os animais de cada unidade experimental.

Ao final do experimento, foi realizada a pesagem dos animais de todas as unidades experimentais para avaliar as variáveis de percentagem de ganho de peso e ganho de peso diário, além da conversão alimentar aparente, sobrevivência e fator de condição, obtidos por intermédio da expressão $\left(\mathrm{wt} / 1 \mathrm{t}^{3} \mathrm{x} 100\right)$, sendo $\mathrm{wt}=$ peso total e $1 \mathrm{t}=$ comprimento total. Os valores de percentagem de ganho de peso e sobrevivência foram transformados pela expressão $\mathrm{y}=\operatorname{arcsen} \sqrt{\mathrm{x} / 100}$, sendo $\mathrm{x}$ o valor desta característica expresso em percentagem para posterior análise estatística.

No segundo experimento (fase de crescimento), foram utilizados 40 animais revertidos, 20 da linhagem comum e 20 da linhagem tailandesa, que foram distribuídos em um delineamento inteiramente casualizado com dois tratamentos e cinco repetições. A unidade experimental constituiu-se de um tanque onde foram estocados quatro animais.

Os valores médios do peso vivo e comprimento inicial para os animais das variedades tailandesa e comum foram de 60,73 e 60,57 g e 15,40 e 15,29 cm respectivamente. Os animais foram distribuídos em 10 tanques de concreto, com capacidade para $500 \mathrm{~L}$, providos de aeração e renovação contínua de água a uma taxa de $25 \%$ ao dia. Os tanques experimentais foram sifonados diariamente para retirada das fezes no período da manhã, antes do fornecimento da primeira alimentação e no período da tarde, antes da última alimentação.

$\mathrm{O}$ arraçoamento foi realizado à vontade e foi utilizada ração comercial na forma extruzada com $3000 \mathrm{kcal} \mathrm{ED} / \mathrm{kg}$ e $28,00 \%$ de PB (Tabela 1 ).
Tabela 1 - Níveis de garantia das rações utilizadas para alimentação de machos revertidos de duas linhagens de tilápia do Nilo

Table 1 - Guarantee levels of the diets fed to reversed males of two Nile tilapia strains

\begin{tabular}{lcr}
\hline $\begin{array}{l}\text { Nutrientes (\%) } \\
\text { Nutrients }\end{array}$ & $\begin{array}{c}\text { Fase } \\
\text { inicial } \\
\text { Starting } \\
\text { phase }\end{array}$ & $\begin{array}{c}\text { Fase de } \\
\text { crescimento } \\
\text { Growing } \\
\text { phase }\end{array}$ \\
\hline $\begin{array}{l}\text { Energia digestível (kcal/kg) } \\
\text { Digestible energy }\end{array}$ & 3000,00 & 3000,00 \\
$\begin{array}{l}\text { Proteína bruta (mínimo) } \\
\text { Crude protein (minimum) }\end{array}$ & 32,00 & 28,00 \\
$\begin{array}{l}\text { Gordura (mínimo) } \\
\text { Fat (minimum) }\end{array}$ & 7,00 & 4,00 \\
$\begin{array}{l}\text { Fibra bruta } \\
\text { (mínimo-máximo) }\end{array}$ & \\
$\begin{array}{l}\text { Crude fiber (minimum- maximum) } \\
\text { Cálcio (mínimo) } \\
\text { Calcium (minimum) }\end{array}$ & $2,00-12,00$ & 12,00 \\
$\begin{array}{l}\text { Fósforo (máximo) } \\
\text { Phosphorus (maximum) }\end{array}$ & 1,00 & 1,20 \\
\hline
\end{tabular}

Ao final do experimento, foram avaliadas as características de peso final, ganho de peso diário, conversão alimentar aparente, comprimento final e fator de condição. Os peixes foram mantidos em jejum por 24 horas e, após, abatidos para analisar as características de carcaça: rendimentos de carcaça (animal sem vísceras e arcos branquiais), rendimento de tronco (carcaça sem cabeça, sem pele e sem nadadeiras dorsais, ventrais e peitorais), de filé; e paralelamente com o abate foram realizadas medidas das características morfométricas dos animais das duas linhagens, sendo comprimentos total, padrão, da cabeça, do tronco e altura e largura do corpo e altura da cabeça segundo LUNDSTEDT et al. (1997) e HURLBLT e CLAY (1998) para avaliação das relações entre as mesmas nas diferentes linhagens de tilápia.

Os parâmetros físico-químicos da água $\mathrm{pH}$, condutividade elétrica $(\mu \mathrm{S} / \mathrm{cm})$, oxigênio dissolvido $(\mathrm{mg} / \mathrm{L})$ foram medidos semanalmente e a temperatura foi tomada diariamente às 8 e $17 \mathrm{~h}$.

Os dados obtidos ao final dos experimentos foram submetidos a análises de variância a $5 \%$ de probabilidade pelo programa SAEG (Sistema de Analises Estatísticas e Genéticas) descrito por EUCLYDES (1983). 


\section{Resultados e Discussão}

Os valores médios das característica de desempenho dos animais das duas linhagens na fase inicial (primeiro experimento) estão apresentados na Tabela 2.

Foram observadas diferenças significativas $(\mathrm{P}<0,05)$ entre as duas linhagens para as variáveis percentagem de ganho de peso, ganho de peso diário, conversão alimentar aparente e sobrevivência, enquanto o fator de condição não diferiu estatisticamente $(P>0,05)$, sendo que os animais da linhagem tailandesa apresentaram os melhores resultados de desempenho na fase inicial.

$\mathrm{Na}$ fase de crescimento (segundo experimento), foram observadas diferenças significativas $(\mathrm{P}<0,05)$ dos tratamentos para as variáveis de ganho de peso, ganho de peso diário e conversão alimentar aparente, sendo que os animais da linhagem tailandesa apresentaram melhores valores que os da linhagem comum (Tabela 3 ).

DAN e LITTLE (2000), avaliando o desempenho de três linhagens de tilápia do Nilo provenientes da Tailândia, Filipinas e Vietnã em dois experimentos, um com duração de 184 dias e outro com 112 dias, em tanques de terra e gaiolas com animais de sexo misto e revertidos, observaram para os animais revertidos criados em tanques de terra no primeiro período melhor desempenho dos animais da linhagem filipina

Tabela 2 - Valores médios de desempenho de machos revertidos de duas linhagens de tilápias do Nilo, na fase inicial

Table 2 - Average performance values of reversed males of two Nile tilapia strains in the starting phase

\begin{tabular}{|c|c|c|c|}
\hline \multirow[b]{2}{*}{$\begin{array}{l}\text { Variáveis } \\
\text { Variables }\end{array}$} & \multicolumn{2}{|c|}{$\begin{array}{l}\text { Linhagens } \\
\text { Strains }\end{array}$} & \multirow[b]{2}{*}{ CV $(\%)$} \\
\hline & $\begin{array}{l}\text { Tailandesa } \\
\text { Thai }\end{array}$ & $\begin{array}{l}\text { Comum } \\
\text { Common }\end{array}$ & \\
\hline $\begin{array}{l}\text { Peso inicial (g) } \\
\text { Initial weight }\end{array}$ & 2,94 & 2,37 & 6,50 \\
\hline $\begin{array}{l}\text { Ganho de peso (\%) } \\
\text { Weight gain }\end{array}$ & $812,43^{a}$ & $644,94^{\mathrm{b}}$ & 8,13 \\
\hline $\begin{array}{l}\text { Ganho de peso diário }(\mathrm{g}) \\
\text { Daily weigth gain }\end{array}$ & $0,48^{\mathrm{a}}$ & $0,31^{\mathrm{b}}$ & 11,76 \\
\hline $\begin{array}{l}\text { Conversão alimentar } \\
\text { Feed:gain ratio }\end{array}$ & $1,15^{\mathrm{a}}$ & $1,31^{\mathrm{b}}$ & 8,53 \\
\hline $\begin{array}{l}\text { Fator de condição } \\
\text { Condition index }\end{array}$ & $1,95^{\mathrm{a}}$ & $2,10^{\mathrm{a}}$ & 8,04 \\
\hline $\begin{array}{l}\text { Taxa de } \\
\text { sobrevivência (\%) } \\
\text { Survival rate }\end{array}$ & $96,00^{\mathrm{a}}$ & $90,00^{b}$ & 10,87 \\
\hline
\end{tabular}

Médias na mesma linha seguidas de letras distintas são diferentes $(\mathrm{P}<0,05)$ pelo teste $\mathrm{F}$.

Means within a row followed by different letters are different $(P<.05)$ by Ftest. e vietnamita quando comparados aos da linhagem tailandesa, já no segundo período observaram um melhor desempenho dos animais da linhagem tailandesa. No cultivo em gaiola no primeiro período observaram um melhor resultado dos animais filipinos não diferindo da linhagem tailandesa e superior aos da linhagem vietnamita, enquanto que no segundo período não foi observada diferença entre as diferentes linhagens. Os autores observaram que todas as linhagens apresentaram ótimo desempenho, principalmente no primeiro período com duração de seis meses em função de temperaturas mais elevadas.

ROMANA-EGUIAeEGUIA(1999), avaliandotilápias vermelhas de linhagens da Tailândia e Filipinas, observaram melhores resultados de desempenho de animais da linhagem tailandesa criados emágua salobra quando comparados a animais da linhagem filipina, entretanto, quando criados em água salgada, os animais da linhagem filipina apresentarammelhores resultados, demonstrando que existem linhagens de tilápia do Nilo melhor adaptadas a certas condições de cultivo que outras.

Os resultados de desempenho do presente experimento concordam com os observados por SALDANHA et al. (1998), os quais demonstraram haver diferença no desempenho entre duas linhagens de $O$. niloticus provenientes de plantéis distintos cultivadas em nossas condições.

Tabela 3 - Valores médios de desempenho de machos revertidos de duas linhagens de tilápias do Nilo, na fase de crescimento

Table 3 - Average performance values of reversed males of two Nile tilapia strains in the growing phase

\begin{tabular}{lccc}
\hline & \multicolumn{2}{c}{ Linhagens } & \\
\cline { 2 - 3 } $\begin{array}{l}\text { Variáveis } \\
\text { Variables }\end{array}$ & $\begin{array}{c}\text { Tailandesa } \\
\text { Thai }\end{array}$ & $\begin{array}{c}\text { Comum } \\
\text { Common }\end{array}$ & CV (\%) \\
\hline $\begin{array}{l}\text { Peso inicial (g) } \\
\text { Initial weight }\end{array}$ & 60,73 & 60,57 & 9,39 \\
$\begin{array}{l}\text { Ganho de peso (\%) } \\
\text { Weight gain }\end{array}$ & $298,48^{\mathrm{a}}$ & $164,41^{\mathrm{b}}$ & 17,98 \\
$\begin{array}{l}\text { Ganho peso diário (g) } \\
\text { Daily weigth gain }\end{array}$ & $2,98^{\mathrm{a}}$ & $1,67^{\mathrm{b}}$ & 12,06 \\
$\begin{array}{l}\text { Conversão alimentar } \\
\text { Feed:gain ratio }\end{array}$ & $1,20^{\mathrm{a}}$ & $1,65^{\mathrm{b}}$ & 7,98 \\
$\begin{array}{l}\text { Fator de condição } \\
\text { Condition index } \\
\text { Taxa de } \\
\text { sobrevivência (\%) }\end{array}$ & $1,83^{\mathrm{a}}$ & $1,97^{\mathrm{b}}$ & 8,07 \\
\begin{tabular}{l} 
Survival rate \\
\hline
\end{tabular} & 100,00 & 100,00 & - \\
\hline
\end{tabular}

Médias na mesma linha seguidas de letras distintas são diferentes $(P<0,05)$ pelo teste $F$.

Means within a row followed by different letters are different $(P<.05)$ by $F$ test. 
Com relação à taxa de sobrevivência foi observado diferença entre as linhagens na fase inicial, com melhor taxa de sobrevivência para os animais da linhagem tailandesa, enquanto na fase de crescimento não foi observada diferença entre as duas linhagens, estes resultados concordam parcialmente com DAN e LITTLE (2000), que, avaliando três linhagens de tilápia do Nilo (tailandesa, filipina e vietnamita) com peso inicial de $10 \mathrm{~g}$, não observaram diferença na taxa de sobrevivência entre as diferentes linhagens.

Com base nos resultados de desempenho inferiores obtidos pelos animais da linhagem comum, quando comparados com os animais importados da Tailândia avaliadas, pode-se observar a necessidade do melhoramento genético do plantel existente em nossa região.

As características de rendimento de carcaça e de filé dos animais de ambas as linhagens não diferiram $(\mathrm{P}>0,05)$, enquanto o rendimento de tronco foi superior nos animais da linhagem comum (Tabela 4). Este fato pode ser explicado pelo melhor fator de condição em que se encontravam. Os rendimentos de carcaça e de filé dos animais de ambas as linhagens ficaram próximos dos obtidos por MACEDO-VIEGAS et al. (1997), avaliando carcaças de tilápia do Nilo em quatro categorias de peso.

Os dados morfométricos obtidos dos 20 animais de cada linhagem, representados por razões morfométricas entre comprimento da cabeça/comprimento padrão (ccab/cp), comprimento da cabeça/ altura da cabeça (ccab/altcab), comprimento padrão/ comprimento total (cp/lt), largura do corpo/compri-

Tabela 4 - Valores médios das características de carcaça de machos revertidos de duas linhagens de tilápias do Nilo, na fase de crescimento

Table 4 - Average carcass characteristics values of reversed males of two Nile tilapia strains in the growing phase

\begin{tabular}{lccr}
\hline & \multicolumn{2}{c}{$\begin{array}{c}\text { Linhagens } \\
\text { Strains }\end{array}$} & \\
\cline { 2 - 3 } $\begin{array}{l}\text { Variáveis } \\
\text { Variables }\end{array}$ & $\begin{array}{c}\text { Tailandesa } \\
\text { Thai }\end{array}$ & $\begin{array}{l}\text { Comum } \\
\text { Common }\end{array}$ & \\
\hline $\begin{array}{l}\text { Peso final (g) } \\
\text { Final weigth }\end{array}$ & $234,75^{\mathrm{a}}$ & $160,66^{\mathrm{b}}$ & 8,95 \\
$\begin{array}{l}\text { Rendimento de } \\
\text { carcaça (\%) }\end{array}$ & $86,88^{\mathrm{a}}$ & $88,29^{\mathrm{a}}$ & 0,93 \\
$\begin{array}{l}\text { Carcass yield } \\
\text { Rendimento de tronco (\%) }\end{array}$ & $49,46^{\mathrm{a}}$ & $51,39^{\mathrm{b}}$ & 0,52 \\
$\begin{array}{l}\text { Trunk yield } \\
\text { Rendimento de filé (\%) } \\
\text { Filet yield }\end{array}$ & $37,47^{\mathrm{a}}$ & $33,37^{\mathrm{a}}$ & 17,89 \\
\hline
\end{tabular}

Médias na mesma linha seguidas de letras distintas são diferentes $(\mathrm{P}<0,05)$ pelo teste $\mathrm{F}$.

Means within a row followed by different letters are different $(P<.05)$ by $F$ test. mento do tronco (larg/ctrc), largura do corpo/altura do corpo(larg/alt) apresentaram diferenças significativas $(\mathrm{P}<0,05)$. Já a relação entre a altura do corpo/ comprimento do tronco (alt/ctrc) não diferiu estatisticamente (Tabela 5). Com base nos dados morfométricos, observa-se que os animais de origem tailandesa apresentaram uma maior relação ccab/cp e maior relação ccab/altcab mostrando que estes animais apresentaram uma cabeça maior em relação aos linhagem comum, por outro lado a relação entre $\mathrm{cp} / \mathrm{lt}$ foi maior para a linhagem tailandesa, o que indica que os animais desta linhagem apresentaram menor tamanho de cauda.

As relações alt/ctrc, larg/alt e larg/ctrc representaram a conformação do filé, embora não tenham sido verificadas diferenças entre alt/ctrc para as linhagens, as razões entre larg/alt e entre larg/ctrc apresentaram valores superiores para a linhagem comum, indicando que estes animais apresentaram-se mais robustos.

Os valores médios dos parâmetros físico-químicos da água $\mathrm{pH}$, condutividade elétrica $(\mu \mathrm{S} / \mathrm{cm})$ e oxigênio dissolvido ( $\mathrm{mg} / \mathrm{L})$, para os experimentos nas fases inicial e de crescimento, constam da Tabela 6 e encontram-se dentro do recomendado para a aqüicultura por SIPAÚBA-TAVARES (1995).

Tabela 5 - Valores médios das características morfométricas de machos revertidos de duas linhagens de tilápias do Nilo, na fase de crescimento

Table 5 - Average morphometric characteristics values of reversed males of two Nile tilapia strains in the growing phase

\begin{tabular}{|c|c|c|c|}
\hline \multirow[b]{2}{*}{$\begin{array}{l}\text { Variáveis } \\
\text { Variables }\end{array}$} & \multicolumn{2}{|c|}{$\begin{array}{l}\text { Linhagens } \\
\text { Strains }\end{array}$} & \multirow[b]{2}{*}{ CV $(\%)$} \\
\hline & $\begin{array}{l}\text { Tailandesa } \\
\text { Thai }\end{array}$ & $\begin{array}{l}\text { Comum } \\
\text { Common }\end{array}$ & \\
\hline $\begin{array}{l}\text { Comprimento cabeça/ } \\
\text { comprimento padrão } \\
\text { Head length/standard length }\end{array}$ & $0,32^{\mathrm{a}}$ & $0,29^{b}$ & 8,18 \\
\hline $\begin{array}{l}\text { Comprimento cabeça/ } \\
\text { altura cabeça } \\
\text { Head length/head height }\end{array}$ & $0,87^{\mathrm{a}}$ & $0,76^{b}$ & 16,20 \\
\hline $\begin{array}{l}\text { Altura corpo/ } \\
\text { comprimento tronco } \\
\text { Body height/trunk length }\end{array}$ & $0,60^{\mathrm{a}}$ & $0,59^{\mathrm{a}}$ & 4,60 \\
\hline $\begin{array}{l}\text { Comprimento padrão/ } \\
\text { comprimento total }\end{array}$ & $0,80^{\mathrm{a}}$ & $0,77^{\mathrm{b}}$ & 3,29 \\
\hline $\begin{array}{l}\text { Standard length/total length } \\
\text { Largura corpo/altura corpo } \\
\text { Body width/body height }\end{array}$ & $0,15^{\mathrm{a}}$ & $0,16^{\mathrm{b}}$ & 8,09 \\
\hline $\begin{array}{l}\text { Largura corpo/ } \\
\text { comprimento tronco } \\
\text { Body width/trunk length }\end{array}$ & $0,27^{\mathrm{a}}$ & $0,29^{b}$ & 7,56 \\
\hline
\end{tabular}

Médias na mesma linha seguidas de letras distintas são diferentes $(P<0,05)$ pelo teste $F$.

Means within a row followed by different letters are different $(P<.05)$ by $F$ test.

Rev. bras. zootec., 30(5):1391-1396, 2001 


\begin{tabular}{|c|c|c|c|c|}
\hline \multirow[b]{2}{*}{$\begin{array}{l}\text { Linhagens } \\
\text { Strains }\end{array}$} & \multicolumn{4}{|c|}{$\begin{array}{l}\text { Fase inicial } \\
\text { Starting phase }\end{array}$} \\
\hline & $\mathrm{pH}$ & $\mathrm{CE}^{1}(\mu \mathrm{S} / \mathrm{cm})$ & $\mathrm{OD}^{2}(\mathrm{mg} / \mathrm{L})$ & $\begin{array}{c}\text { Temperatura }\left({ }^{\circ} \mathrm{C}\right) \\
\text { Temperature }\end{array}$ \\
\hline Tailandesa (Thai) & 7,41 & 0,20 & 7,21 & 26,42 \\
\hline Comum & 7,38 & 0,21 & 7,29 & 26,60 \\
\hline \multicolumn{5}{|l|}{ Common } \\
\hline CV (\%) & \multicolumn{4}{|c|}{$\begin{array}{c}\text { Fase de crescimento } \\
\text { Growing phase }\end{array}$} \\
\hline Tailandesa (Thai) & 7,17 & 0,13 & 5,10 & 26,44 \\
\hline $\begin{array}{l}\text { Comum } \\
\text { Common }\end{array}$ & 7,17 & 0,13 & 5,12 & 26,44 \\
\hline
\end{tabular}

${ }_{1}^{1}$ Condutividade elétrica (electric conductivity).

2 Oxigênio dissolvido (Dissolved oxygen).

\section{Conclusões}

Os animais da linhagem tailandesa na fase de crescimento apresentaram cabeça maior e cauda menor em relação à linhagem comum e os comuns, maior rendimento de tronco, porém o rendimento de filé foi semelhante nas duas linhagens.

Os animais da linhagem tailandesa apresentaram melhores resultados de ganho de peso e conversão alimentar nas fases inicial e de crescimento.

\section{Referências Bibliográficas}

BORGHETTI, J.R., OSTRENSKY, A. Estratégias e ações governamentais para incentivar o crescimento da atividade aquicola no Brasil. In: CONGRESSO SUL-AMERICANO DE AQUICULTURA, 1, 1998, Recife, PE. Anais... Recife: SIMBRAQ, 1998, Recife, 1998. p.437-447.

DAN, N.G., LITTLE, D.C. 2000. The culture performance of monosex and mixed-Sex new-season and overwintered fry in the three strains of Nile tilapia (Oreochromis niloticus) in northen Vietnã. Aquaculture, 184:221-231.

EL-SAYED, A.F.M. 1999. Alternative dietary protein sources for farmed tilapia, Oreochromis spp. Aquaculture, 179:149-168.

EUCLYDES, R.F. 1983. Manual de utilização do programa SAEG (Sistema para Análises Estatísticas e Genéticas). Viçosa: UFV. 53p.

HAYASHI, C. 1995. Breves considerações sobre as tilápias. In: RIBEIRO, R.P., HAYASHI, C., FURUYA, W.M. (Eds.) Curso de piscicultura-Criação racional de tilápias. p.4.

HURLBUT, T., CLAY, D. 1998. Morphometric and meristic differences between shallow and deep-water populations of white hake (Urophycis tenuis) in the southern Gulf of St. Lawrence. Can. Anim. Sci., 55:2274-2282.

LAHAV, E., RA'NAN, Z. 1997. Salinity tolerance of genetically produced tilapia (Oreochromis) hybrids. Isr. J. Aquac., 49(3):160-165.

LAZARD, J., ROGNON, X. 1997. Genetic diversity of tilapia and aquaculture development in Côte D'Ivoire and Niger. Isr. J. Aquac., 49(2):90-98.
LOVSHIN, L.L., CYRINO, J.E.P. Status of commercial fresh water fish culture in Brazil. In: SIMPÓSIO SOBRE MANEJO E NUTRIÇÃO DE PEIXES, 2, 1998, Piracicaba. Anais... Piracicaba: CBNA, 1998. p.1-20.

LOVSHIN, L.L. Tilapia farming: a growing worldwide aquaculture industry. In: SIMPÓSIO SOBRE MANEJO E NUTRIÇÃO DE PEIXES, 1, Piracicaba, 1997. Anais... Piracicaba: CBNA, 1997. p.137-164.

LOVSHIN, L.L. Red tilapia or Nile tilapia: which is the best culture fish? In: SIMPÓSIO SOBRE MANEJO E NUTRIÇÃO DE PEIXES, 2, Piracicaba, 1998. Anais... Piracicaba: CBNA, 1998. p.179-198.

LUNDSTEDT, L.M., LEONHARDT, J.H., DIAS, A.L. 1997. Alterações morfométricas induzidas pela reversão sexual em tilápias do Nilo Oreochromis niloticus (Linnaeus, 1757), R. Unimar, 19(02):461-472.

MACEDO-VIEGAS, E.M., SOUZA, M.L.R., KRONKA, S.N. 1997. Estudo da carcaça de tilápia do Nilo (Oreochromis niloticus) em quatro categorias de peso. R. Unimar, 19(3):863-870.

POPMA, T.J., PHELPS, R.P. Status report to commercial tilápia producers on monose $\mathrm{x}$ fingerling productions techniques. In: AQUICULTURA BRASIL'98, 1998, Recife. Anais... Recife: SIMBRAQ, 1998. p.127-145.

ROMANA-EGUIA, M.R.R., EGUIA, R.V. 1999. Growth of five red tilapia strains in saline enviroments. Aquaculture, 173(1-4):161-170.

SALDANHA, A.C.A., SILVA, A.L.N., SANTOS, E.C.L. 1998. Estudo comparativo do desempenho entre quatro linhagens de "tilápias" (Oreochromis spp). In: CONGRESSO SULAMERICANO DE AQUICULTURA, 1, Recife, 1998. Resumos... Recife: SIMBRAQ, 1998. p.257.

SIDDIQUI, A.Q., AL-HARBY, A.H. 1995. Evaluation of three species of tilapia, red tilapia and hybrid tilapia as culture species in Saudi Arabia. Aquaculture, 138(1-4):145-157.

SIPAÚBA-TAVARES, L.H.S. 1995. Limnologia aplicada à aqüicultura. Jaboticabal: FINEP. 70p. 